\title{
O equilíbrio do poder na história do pensamento político democrático: da constituição mista à separação de poderes e o bicameralismo
}

\section{The balance of power in the history of democratic political thought: From the mixed Constitution to the separation of powers and the bicameralism}

\section{Rodolfo Porto Darrieux ${ }^{1}$}

\section{Resumo}

A proposta deste artigo é demonstrar a evolução no pensamento político democrático no que tange ao equilíbrio do poder. Equilibrar o poder de modo a evitar a tirania sempre foi um objeto importante na história do pensamento político democrático. Vemos que tal preocupação se iniciou na Grécia Antiga com Aristóteles enxergando o equilíbrio social através da constituição mista como uma forma de evitar a tirania, passando por Políbio e Maquiavel.

\footnotetext{
${ }^{1}$ Possui graduação em Ciências Sociais pela Universidade Federal do Rio de Janeiro e mestrado em Ciência Política no Instituto de Estudos Sociais e Políticos/UERJ. Email: rodolfo_scotelaro@hotmail.com

Revista Cadernos de Estudos Sociais e Políticos, v. 5, n. 9, jan-junho 2016 
Posteriormente, com o aumento da abrangência social e territorial do Estado nacional na era moderna, pensadores como John Locke, Montesquieu e James Madison perceberam o papel das instituições para que o abuso de poder fosse evitado pelos representantes políticos eleitos. Através do artigo, vemos que o conceito de constituição mista não foi posto de lado na era moderna.Vemos nos teóricos políticos liberais que esta noção deu origem ao bicameralismo moderno.

Palavras-chave: equilíbrio do poder, constituição mista, separação de poderes.

\begin{abstract}
The proposal of this paper is to demonstrate the evolution in the democratic political thought concerning the balance of power. Balancing the power in a way to avert tyranny has always been an important object in the history of democratic political thought. We notice that such preoccupation started in Ancient Greece with Aristotle conceiving the social balance on the mixed constitution as a way to avoid tyranny, passing by Polybius and Machiavelli. Afterwards, with the increase in the social and territorial coverage of the national State in modern era, thinkers such as John Locke, Montesquieu and James Madison perceived the role of institutions to avoid elected political representative's tyranny. According to the article, we see that the conception of mixed constitution was not forgotten in the modern age. We notice in the liberal political theorists that this notion "gave birth" to modern bicameralism.
\end{abstract}

Revista Cadernos de Estudos Sociais e Políticos, v. 5, n. 9, jan-junho 2016 
Keywords: balance of power, mixed constitution, separation of powers.

Revista Cadernos de Estudos Sociais e Políticos, v. 5, n. 9, jan-junho 2016 


\section{Introdução}

Aquilo que "Estado" e "política" têm em comum (e é inclusive de sua intercambialidade) é a referência ao fenômeno do poder (...). Não há teoria política que não parta de alguma maneira, direta ou indiretamente, de uma definição de "poder" e de uma análise do fenômeno. Por longa tradição o Estado é definido como summa potestas (...). A teoria do Estado apoia-se sobre a teoria dos três poderes (o legislativo, o executivo e o judiciário) e das relações entre eles (Bobbio, 2011:76).

Quando observamos autores que se debruçaram sobre o tema da democracia, seja visando conceber um governo ideal e equilibrado (Aristóteles, 2012; Políbio, 1985) ou buscando evitar um governo autoritário (Locke, 1979; Montesquieu, 1979; Hamilton et al., 2001), vemos que o controle de quem detém o poder político e como esse poder se organiza sempre foram questões levantadas por diferentes pensadores. No entanto, ambas escolas de pensamento têm um elemento em comum, de certa forma: ambas visam evitar a tirania. Até durante metade do século V a.C, as cidades-estado gregas eram controladas por aristocratas, monarcas ou oligarcas quando, a partir de então, homens livres adquiriram status de cidadãos e assim passaram a ter direito a participar do governo (Dahl, 2012). Foi neste cenário que surgiram ideias nas quais um povo soberano tem o direito de se governar e dispor de instituições para tal fim.

A concepção de constituição mista de Aristóteles (2012) é o registro mais antigo que temos quando centramos na questão do equilíbrio do poder como elemento fundamental para o bom funcionamento do governo. Esta noção

Revista Cadernos de Estudos Sociais e Políticos, v. 5, n. 9, jan-junho 2016 
teve impacto muito grande no desenho institucional das cidades-estado gregas, sobretudo Atenas (Aristóteles, 2012), na República romana (Políbio, 1985)e, já no início da era moderna, a concepção de governo misto é retomada com o resgate do republicanismo feito por Maquiavel (1979). A constituição mista parte do pressuposto de que o equilíbrio do poder ocorre quando diferentes formas de governo se combinam.

Com o advento das revoluções burguesas resultando em sistemas políticos de grande escala populacional e territorial, sobretudo no século XVIII,surgiu a noção de governo representativo, que em oposição ao Absolutismo monárquico deveria encontrar mecanismos institucionais capazes de evitar a concentração de poder nas mãos de um só representante. Surge então a teoria da separação de poderes com Montesquieu (1979) que, posteriormente, serviu de grande influência para Hamilton et al. (2001) considerá-la e, a partir dela, desenhar o sistema político dos Estados Unidos.Surgem aí as ideias de governo limitado e moderado. Porém, pontos considerados pela concepção de constituição mista não foram postos de lado.

A partir das considerações acima, o objetivo deste trabalho é demonstrar como se deu a evolução da ideia de equilíbrio do poder dentro do pensamento político democrático e seus principais desdobramentos institucionais. Conhecer o desenvolvimento das ideias acerca do controle do poder é de suma importância para a compreensão não só da história do pensamento político, mas dos desenhos institucionais das democracias liberais modernas presentes em grande parte dos países ocidentais.

Para mostrar o desenvolvimento da ideia do equilíbrio de poder, o trabalho é ordenado da seguinte maneira: no primeiro tópico, analiso o desenvolvimento 
da noção de constituição mista ressaltando os objetivos buscados pelos seus pensadores ressaltando seu impacto no pensamento republicano ${ }^{2}$ e a origem e evolução da ideia de separação de poderes na modernidade; no segundo tópico, mostro os resultados institucionais gerados pelo debate do equilíbrio do poder levando em consideração principalmente o resultado institucional moderno da constituição mista; por fim, na conclusão, realizo as considerações finais.

Os resultados encontrados através da leitura desses autores, levando em consideração seus contextos históricos, são de que a constituição mista possui um "herdeiro" moderno: o bicameralismo, que ao lado da separação de poderes, na modernidade tem como objetivo o "controle do poder pelo poder", além de fazer um balanço entre diferentes tipos de representação política.

\section{Democracia, governo misto e separação de poderes}

A noção de governo misto surge com Aristóteles (2012) na Grécia Antiga. Uma das principais preocupações de Aristóteles era a de tipificar as diferentes formas de governo de modo que fosse possível para o autor elencar virtudes e vícios de cada tipo de governo (Bobbio, 1976; Chatelet et al., 1982).

\footnotetext{
${ }^{2}$ A constituição mista foi importante no desenho das instituições políticas estamentais da Idade Média, tendo Santo Tomás de Aquino foi seu principal teórico. No entanto, neste artigo, este autor não é considerado, uma vez que não se enquadra no pensamento político democrático.
}

Revista Cadernos de Estudos Sociais e Políticos, v. 5, n. 9, jan-junho 2016 
Aristóteles (2012) argumenta que são três as formas de governo ${ }^{3}$ : Monarquia (governo de um só), Aristocracia (governo de poucos) e Politeia (o governo de muitos). No entanto, vemos que para o autor nenhuma dessas formas de governo consegue atender ao que ele alega ser o essencial da política: o bem comum. O resultado de todas elas é um governo viciado, pois somente uma parte do corpo social teria acesso ao poder político. Nesse sentido, a monarquia se torna Tirania, a Aristocracia se torna Oligarquia e a Politeia, por sua vez, se transforma em Democracia.

Assim, de modo a evitar as diferentes formas de Tirania, Aristóteles (2012) argumentava que os cidadãos não possuem nenhum outro senhor senão a lei. Mas, mais que isso, para garantir que os interesses de cada grupo social não sejam esquecidos, e assim para que o poder numa determinada sociedade política não encontre em desequilíbrio, o governo ideal para Aristóteles é a Politeia, que no caso, é a mistura da Oligarquia e da Democracia. Ou seja, duas formas viciadas de governo geram o melhor dos governos. Isto ocorre porque nesse regime ocorre a fusão de duas causas de elementos sociais divergentes: a luta entre os que não possuem nada (pobres) e os proprietários (ricos). Ou seja, quanto mais próxima de uma classe social média, mais justo seria o governo para Aristóteles (Bobbio, 1976). Desse modo, os dois elementos sociopolíticos extremos Oligarquia e Democracia não conseguem obter poder excessivo.

3 É importante levar em consideração que o critério para a classificação destes governos por todos os autores que abordam o tema da constituição mista é numérico. Ou seja, a preocupação não só de Aristóteles (2012), como também de Políbio (1985) e Maquiavel (1979), é a quantidade de pessoas que detêm o poder soberano.

Revista Cadernos de Estudos Sociais e Políticos, v. 5, n. 9, jan-junho 2016 
Políbio (1985), por sua vez, muito influenciado pelo pensamento aristotélico, talvez tenha sido o principal expoente quando o assunto é governo misto. Através de sua análise realizada sobre a Constituição romana, Políbio (1985), assim como Aristóteles, buscou analisar as diferentes tipologias das formas de governo.

A tese de Políbio (1985) é a de que todas as constituições simples são más porque são simples. A constituição mista é um governo que combina as três formas clássicas. Nota-se claramente aí a atribuição que Políbio denota à constituição mista como capaz de assegurar a estabilidade. Para ele, as seis formas de governo simples são cíclicas e fatalistas ao longo da história, ou seja, são instáveis. A combinação das três formas virtuosas (Reino, Aristocracia e Politeia) em uma só resultaria num governo estável.

O caráter particular da constituição mista de Políbio está em trazer a nível institucional o conflito de classes. Isto que o diferencia com relação a Aristóteles, onde a resolução do conflito deveria ocorrer na esfera social, através de uma sociedade sem grandes desequilíbrios sociais. Políbio (1985) traz a resolução do conflito para o meio político, ou seja, institucionaliza o conflito social através de um governo misto e seu sistema de controle recíproco.

Nicolau Maquiavel (1979) é sem dúvida um pensador muito influenciado pelo pensamento polibiano. Maquiavel (1979), resgatando as ideias republicanas clássicas após a Idade Média, sustentou que existem três tipos de governo: Principado, Aristocracia e Popular além de suas formas degenerativas. Para o pensador florentino, as formas de governo são cíclicas, iniciando-se com o Principado, se tornando Tirania, posteriormente se

Revista Cadernos de Estudos Sociais e Políticos, v. 5, n. 9, jan-junho 2016 
tornando Aristocracia, se degenerando em Oligarquia e assim sucessivamente. É na República, sustenta Maquiavel (1979) ao buscar compreender os fatores que levaram ao longo domínio político de Roma na Antiguidade, que a representação simultânea de três bases sociais de cada um dos tipos confere ao poder da organização política um máximo de estabilidade capaz de ser alcançado. Isso ocorre porque uma República possui maior capacidade de adaptação às variações do tempo e das diversas situações.

Ribeiro de Oliveira (2006) alega que, em Maquiavel, estabilidade não significa consenso, e sim conflito aberto entre "as duas fontes de oposição" a qualquer governo, povo e elite. Assim, Maquiavel não considera o conflito entre classes como algo ruim, e sim como motor capaz de gerar o anseio pela boa legislação e liberdade política. O equilíbrio deve ser buscado dentro do social e não pautado através da institucionalização de classes. Nesse aspecto, Maquiavel se afasta do modelo polibiano e se aproxima do aristotélico, no entanto, considerando que a desarmonia social não é ruim. A desunião como reflexo da sociedade passa a representar a capacidade criativa do movimento democrático. Maquiavel, assim, abre espaço para que a observação da história política deixe de ser cíclica, podendo haver assim "aberturas" para mudanças no campo político e social (Negri, 2002). Porém, essas mudanças só são positivas para Maquiavel (1979) uma vez que o poder se encontre equilibrado através de uma constituição republicana mista, garantindo a participação no poder das duas camadas sociais consideradas.

Dahl (2012) sustenta que a tradição republicana retomada por Maquiavel (1979) na modernidade foi "reformulada, remodelada e reinterpretada" na 
Inglaterra e nos Estados Unidos dos séculos XVII e XVIII (Pocock, 1975; Wood, 1986).

Com o fim do Renascimento e expansão do regime capitalista e Estados nacionais, principalmente a partir do século $\mathrm{XV}$, a noção de republicanismo maquiavélico sofreu reformulações profundas. Era um fator inevitável, uma vez que as sociedades se tornaram muito mais numerosas e heterogêneas do que em relação às cidades-estado gregas e às Repúblicas que compreendiam o atual Estado italiano. Dahl (2012) nos demonstra que os pensadores republicanos começaram a perceber que o conceito de interesses no republicanismo clássico era muito simples frente à realidade pela qual se deparavam. Não havia mais a possibilidade, por exemplo, dos "homens livres" se reunirem na Ágora, uma vez que uma série de fatores impedia tal fator: grandes distâncias e negócios privados, entre outros. Surgem, assim, duas escolas de pensamento: o liberalismo e o constitucionalismo, além da noção de governo representativo. A consolidação do pensamento liberal pode ser atribuída a John Locke (1979), que concebeu a propriedade privada como algo natural ao indivíduo. Em suma, o liberalismo aborda a importância de um Estado mínimo não intervencionista na esfera privada. Por sua vez, o constitucionalismo indica que o "contrato social" deve limitar o poder dos representantes e garantir direitos individuais (Locke, 1979; Rousseau, 1979; Chevallier, 1980).

Vemos em Locke (1979) que o Estado deve garantir o direito de propriedade e proteger a comunidade de perigos internos e externos. É na origem e finalidade do governo civil que Locke assenta a divisão do poder comum na comunidade política em Executivo, Legislativo e Federativo. Em outras palavras, Locke leva o debate acerca do equilibro do poder para o campo

Revista Cadernos de Estudos Sociais e Políticos, v. 5, n. 9, jan-junho 2016 
institucional. Segundo Locke, o poder Legislativo se caracteriza como o poder supremo da comunidade sobre os demais poderes, pois se trata do poder capaz de definir leis e, dessa maneira, ele deve ser superior a quem as executa. Ninguém investido de quaisquer outros poderes, que não seja o consentimento público para legislar, poderá fazer leis que tenham a obrigatoriedade de serem cumpridas. $\mathrm{O}$ poder Executivo e o poder Federativo, que Locke afirma serem passíveis de se encontrar sob o poder de um único magistrado, estão sob o controle do poder Legislativo e dele dependem as suas ações.

Locke acredita que não há necessidade nem conveniência da constante reunião do poder Legislativo. Com as leis estabelecidas, a assembleia só se recomporia quando houvesse necessidade. É nesse cenário que entra a necessidade de um poder Executivo (poder este exercido por um principe ${ }^{4}$ ), desde que limitado pelas leis do Legislativo.

Já o poder Federativo se encarrega das relações exteriores da comunidade. No entanto, Locke deixa claro que este poder deve ser submetido ao Executivo $^{5}$. O autor argumenta que este poder é menos suscetível a guiar-se por leis positivas de tal forma que melhor seria que ele estivesse nas mãos daquele que já estaria habituado a agir com prudência e sabedoria com relação ao tratamento do bem público.

Em Locke fica bem claro que, independentemente da forma de governo, o poder Legislativo e o Executivo não devem ser controlados simultaneamente

\footnotetext{
${ }^{4}$ Um indivíduo cuja autoridade política advém do Legislativo.

${ }^{5}$ Ou seja, na verdade, não há uma separação de poderes stricto sensu entre Executivo e Federativo em Locke. O fato é que Locke atribui ao chefe do poder Executivo a prerrogativa de legislar sobre política externa.
}

Revista Cadernos de Estudos Sociais e Políticos, v. 5, n. 9, jan-junho 2016 
pelos mesmos indivíduos representantes da comunidade política. Segundo ele, porém, não há uma divisão rígida entre os poderes, uma vez que cabe ao poder Legislativo designar o encarregado do poder Executivo e este possui o chamado Federativo. Além disso, quanto a quem o Estado deve representar, em Locke esta questão se restringe aos donos de propriedade, logo, não é uma preocupação do autor o equilíbrio social na política através da constituição mista. Nesse sentido, ele está preocupado exclusivamente com o equilíbrio do poder nas funções do Estado, de modo que os representantes não se tornem tirânicos.

Montesquieu (1979), influenciado por Locke e adepto do pensamento constitucionalista moderno, pode ser considerado de facto o primeiro pensador a conceber que o poder não pode ser uno, e sim tripartite, sem que as funções de cada poder se sobrepujassem a de outro, evitando assim que a mesma pessoa exercesse ao mesmo tempo mais de uma das funções essenciais do Estado (Wilson, 1934). Esse é o que é chamado por Montesquieu de governo moderado, onde se revela a única solução institucional da liberdade política (Châtelet et. al, 1985). Somente com moderação os governos têm a possibilidade de funcionar de maneira estável. Diferentemente de Locke (1979), Montesquieu faz do Judiciário um poder distinto, enquanto que Locke não realiza essa separação (Chevallier, 1980).

Em busca das condições capazes de delinear um regime estável, Montesquieu analisa dois aspectos: a tipologia dos governos e a teoria da separação dos três poderes. A partir do pressuposto levantado por Montesquieu acerca do que é o espírito das leis, as leis mantém relações com a natureza e com o princípio de cada tipo de governo. São três os tipos de governo estipulados por Montesquieu: republicano, monárquico e despótico.

Revista Cadernos de Estudos Sociais e Políticos, v. 5, n. 9, jan-junho 2016 
Nas Repúblicas (forma esta que, segundo Montesquieu, se encontra superada devido ao aumento da abrangência territorial que as instituições políticas ocupam com a centralização no Estado nacional), o poder é detido pelo povoe sua mola é a virtude ${ }^{6}$.

Nas monarquias, um rei governa através de leis estabelecidas e seu princípio é a honra. Para que a monarquia funcione com plenitude deve existir uma ligação essencial entre o rei e a nobreza. A detenção do poder por um só não basta; o modo de exercício através de leis supõe a existência de poderes intermediários subordinados e dependentes (Châtelet et al.,1985; Bobbio, 1976).

No Despotismo, o governo também se pauta pelo exercício da soberania de um só, e como nesse governo "todos os homens são iguais e escravos de seu soberano" (Montesquieu, 1979), o medo é seu princípio. Pode-se dizer que esta seria uma forma degenerada dos outros dois tipos de governo.

No sistema político inglês, Montesquieu (1979) encontra empiricamente o que para ele é considerado como uma Constituição perfeita. Para o autor, a monarquia inglesa seria reflexo de um regime onde a nobreza se tornou importante nos negócios públicos, se aproximando da burguesia, mantendo assim a estabilidade do governo daquele país. Assim, Montesquieu elogia o Parlamento bicameral britânico com a Câmara Alta constituída pela nobreza e a Câmara dos Comuns, eleita pelo voto popular além das funções dos três poderes. Trata-se de uma comparação entre Despotismo e monarquia como a forma de governo em que há uma faixa de poderes intermediários entre os súditos e o soberano: os "contra-poderes", que impedem o abuso, pelo

\footnotetext{
${ }^{6}$ Traduz-se "virtude" como apreço aos negócios públicos.
}

Revista Cadernos de Estudos Sociais e Políticos, v. 5, n. 9, jan-junho 2016 
monarca, da sua própria autoridade (Bobbio, 1976). Sendo assim, esses contra-poderes são corpos que exercem funções estatais que são capazes de frear o acúmulo do poder num só grupo político. Temos aqui, o chamado controle vertical do poder.

A partir da análise sobre a Constituição da Inglaterra, Montesquieu começa a desenvolver o que Bobbio (1976) denominou de divisão horizontal do poder. Aí reside a tão famosa e influente divisão entre os três poderes, que foi de enorme importância para a formação de Constituições na modernidade.

Tratou Montesquieu assim, da chamada teoria tripartite, que consiste em atribuir ao Estado as três esferas de poder: o Legislativo, segundo o qual se fazem as leis para sempre ou para determinada época, bem como se aperfeiçoam ou revogam as que já se acham feitas; o Executivo, que se ocupa o príncipe ou magistrado das relações exteriores e da segurança dos cidadãos; e finalmente o Judiciário, que dá ao príncipe ou ao magistrado a faculdade de punir ou julgar os crimes da ordem civil. Nesta tese, Montesquieu pensa em não deixar nas mesmas mãos, as tarefas de legislar, administrar e julgar em observância às normas legais vigentes, pois, segundo o autor, a experiência da história política mostra que todo o homem que tem o poder é levado a abusar dele, indo até onde possa encontrar limites. A desconcentração do poder é uma solução institucional que procura estabelecer uma relação de equidade, onde nenhum poder faça de si mesmo condição de absoluto dentro das relações entre os membros da sociedade.

O poder Executivo para Montesquieu deve ser exercido por uma pessoa, pois assim é mais bem exercido, pois tem a "necessidade de uma ação 
momentânea" (Montesquieu, 1979) sem deixar de relevar a importância da legitimação sob o poder Legislativo.

Quanto ao poder Judiciário, este não deve ser entregue a um grupo permanente de pessoas, mas por pessoas tiradas do seio do povo, em certas épocas do ano, para a formação de um tribunal que permanecerá ativo somente até a exigência de sua necessidade.

O poder Legislativo em Montesquieu, por sua vez, é o que deve receber maiores atenções. Janet (2012) argumenta que em Montesquieu (1979) o poder Legislativo por si só não garante um equilíbrio satisfatório, funcionando de maneira "unitária" ao lado dos outros poderes. O poder Legislativo deve congregar os elementos "nobres" e "populares", daí o motivo de Montesquieu elogiar o parlamento britânico dividido entre Câmara dos Lordes e dos Comuns. Por isso, Montesquieu considera o governo monárquico o mais justo, pois, além da separação tripartite, ele congrega os três elementos sociais: o Legislativo bicameral com os elementos aristocráticos e democráticos e o Executivo, o monárquico (rei). Sendo assim, esta disposição institucional pensada por Montesquieu pode ser considerada como a versão moderna da teoria clássica da constituição mista, já que há uma unidade de inspiração no governo misto e no "governo moderado" pensado por Montesquieu (Chevallier, 1980).

Posteriormente, no ainda nascente Estados Unidos da América, o pensamento de Montesquieu se fez muito influente no desenho institucional daquele país através dos autores federalistas. Châtelet et al. (1985) argumentam que o papel dos federalistas teve uma importância significativa em considerar o "papel motor das instituições" em um sentido mais determinante do que no

Revista Cadernos de Estudos Sociais e Políticos, v. 5, n. 9, jan-junho 2016 
caso europeu. Estas, segundo os autores, possuíam a função de criadoras da nova nação, caracterizando um "nacionalismo institucional".

Vemos através dos escritos federalistas, principalmente os de James Madison e Alexander Hamilton, que o desenho institucional feito pelos founding fathers tinha como objetivo primordial montar um Estado nacional com base nas ideias liberais de Locke e Montesquieu (Bellamy, 1996). Essas instituições políticas refletem uma concepção de democracia menos ligada à noção de vontade popular e sim à de um jogo político controlado por essas instituições a fim de garantir a liberdade e evitar o que Tocqueville (2005) nomeia de "tirania da maioria" ${ }^{7}$. Tocqueville (2005) se mostra um verdadeiro entusiasta das instituições democráticas e liberais norte-americanas por serem efetivas justamente na contenção das "paixões" da maioria.

No entanto, nos Estados Unidos faltam dois elementos sociopolíticos que, por sua vez, eram encontrados na Inglaterra e na França: a nobreza (Aristocracia) e o rei (Monarquia).Dessa maneira, o país só poderia ter instituições que dessem conta da divisão e controle das funções do Estado, ou seja, da divisão tripartite (Wilson, 1934). Uma nação fundada por supostos indivíduos "iguais" não teria como estabelecer instituições que levassem em conta o equilíbrio de interesses de grupos sociais distintos (Manin, 1994).

\footnotetext{
7 Alexis de Tocqueville (2005) desenvolve tal conceito para rotular os sistemas políticos nos quais a maioria dita as regras, sem apelo por justiça ou equidade. Seu principal problema é que a maioria solapa as minorias e opiniões discordantes minoritárias dentro da sociedade.
}

Revista Cadernos de Estudos Sociais e Políticos, v. 5, n. 9, jan-junho 2016 
Porém, Wilson (1934), citando a obra Defence of the Constitutions of Government of the United States of America (1786), de John Adams ${ }^{8}$, argumenta que este autor, junto a James Madison,concebeu um arranjo institucional com base no governo misto além da separação de poderes concebida por Locke, mas sistematizada por Montesquieu, que fosse capaz de equilibrar interesses econômicos divergentes da sociedade.

Adams considera importante que uma Casa Legislativa represente os interesses econômicos conservadores da sociedade, para que o "perigo do ataque democrático" se consolide e ponha em risco a liberdade política. Seguindo essa lógica, Adams acaba sendo um defensor do governo representativo, da separação de poderes e um governo misto equilibrado em três ramos: a Presidência (como herdeira do poder monárquico), o Senado (como representante dos grupos econômicos conservadores) e Câmara de Representantes como espaço da representação do elemento democrático. Wilson (1934) alega que Adams para suprir a ausência do elemento aristocrático no contexto norte-americano e que, por sua vez, era o centro do balanço dos governos mistos europeus, percebeu a presidência ou $\mathrm{o}$ Executivo como a principal instância de poder para equilibrar os interesses do Senado e da Câmara. Hamilton et al. (2001), no artigo $\mathrm{n}^{\circ} 10$ dos Federalistas, para frear o ímpeto das facções políticas e o conflito de classe emergente das divergências econômicas, atribui ao Senado o papel de principal moderador das forças políticas, assim como Adams.

No que tange à separação de poderes nos federalistas, vemos que Madison no artigo $\mathrm{n}^{\circ} 51$, se baseia bastante em Montesquieu, visto que o objetivo de

\footnotetext{
${ }^{8}$ Foi presidente dos Estados Unidos entre os anos de 1797 e 1801.
}

Revista Cadernos de Estudos Sociais e Políticos, v. 5, n. 9, jan-junho 2016 
desenhar essas instituições é basicamente o mesmo: evitar o acúmulo de poder nas mãos de um mesmo representante ou grupo de representantes e magistrado.

Por fim, vemos que o equilíbrio do poder foi uma preocupação constante dos teóricos do Estado desde a Antiguidade até o advento do Liberalismo na Idade Moderna. Com a emergência dos governos representativos na Idade Moderna, o acúmulo de funções num determinado representante ou grupo de representantes se tornou uma preocupação. Assim, para evitar a tirania e que "o poder controle o poder" (Hamilton et al., 2001), surgiu a ideia de separação de poderes (Locke, 1979; Montesquieu, 1979; Hamilton et al., 2001). Por sua vez, a noção de constituição mista clássica sofreu um baque muito grande quando países sem uma "aristocracia natural" surgiram, como foi o caso dos Estados Unidos. Assim, essa ideia de constituição mista com base em camadas sociais que aparece até Montesquieu vai gradualmente desaparecendo, deixando como "herança" o bicameralismo. Ou seja, de certa forma o caráter da camada social no equilíbrio vai se perdendo em função da noção de igualdade entre indivíduos ter sido triunfante a partir da Era Moderna. Se a partir deste período os indivíduos são iguais perante uma Constituição, por que ainda encontramos países, como o próprio Brasil, cujo modelo de legislatura é bicameral? No tópico a seguir, discorro sobre esta questão.

\section{Alguns resultados institucionais do debate nos estados-nação modernos: o bicameralismo nos Estados Unidos e no Brasil}


Como visto no tópico anterior, além da inserção de instituições que visam garantir um "equilíbrio dinâmico" (Wilson, 1934) das funções dos magistrados e representantes políticos, para que "o poder controle o poder" (Hamilton et al., 2001), e evite assim que haja acúmulo de atribuições num só corpo de representantes, o que poderia incentivar atitudes tirânicas, a noção de constituição mista em razão das mudanças no corpo social se tornaram obsoletas, principalmente nas "novas nações". Tal fato caracterizou um desafio para os federalistas norte-americanos, visto que não havia aristocracia naquele país. Logo, qual seria o motivo de manter duas casas legislativas?

A decisão de manter o Legislativo dividido em duas câmaras (Senado e Câmara dos Representantes)se deve à percepção de autores como Hamilton et al. (2001) e Adams acerca do fato de que, apesar da sociedade norteamericana ser regida sob a égide do igualitarismo, os interesses eram economicamente conflitantes dentro dessa mesma sociedade, o que poderia resultar em uma "tirania da maioria" (Tocqueville, 2005) e facções políticas radicais (Hamilton et al., 2001).

Nessa lógica, o Senado norte-americano passou a ser uma instituição representativa de interesses de "pessoas renomadas", com uma quantidade substantiva de propriedade, no qual o objetivo era frear as paixões e a instabilidade existentes na Câmara de Representantes, pois esta tinha sua composição formada através do voto popular. No entanto, a partir do final do século XIX e início do século XX, a opinião pública norte-americana passou a encarar o Senado como uma instância que beneficiava certos grupos econômicos, por seus membros se tratarem da elite socioeconômica do país. 
Tais pressões resultaram na ratificação da Emenda 17 em 1913, quando a composição do Senado foi alterada, passando a ser dois senadores por estado eleitos pelo voto popular. Os senadores passam assim a ser representantes de um determinado estado, eleitos pelo voto majoritário.

Já que desse modo a lógica da representação não parte mais do aspecto socioeconômico, por que a manutenção do Senado e, consequentemente, do sistema bicameral até os dias atuais? A decisão de manter a Câmara Alta foi motivada pelo próprio princípio de checks and balances que a constituição mista acabava garantindo (Wilson, 1934). Ao lado disso, é uma maneira de garantir a conciliação de um governo da maioria, porém preservando as liberdades de certas minorias. Isso ocorre devido ao modo como o Senado é composto eleitoralmente. Como os senadores são eleitos por voto majoritário num determinado estado, seu eleitorado é muito mais heterogêneo do que o de um deputado, uma vez que apesar do voto deste também ser majoritário seu eleitorado compreende um distrito de menores proporções em termos geográficos e populacionais (Rabat, 2002): "Esses interesses dispõem de real poder institucional de negociação e veto, pois a faculdade de legislar repartese simetricamente" (ibidem, 2002).

Em termos de produção legal, ambas as casas possuem praticamente as mesmas iniciativas legislativas e função de casa revisora com poder de emenda. Porém, restringe-se à Câmara dos Representantes, a iniciativa de

Revista Cadernos de Estudos Sociais e Políticos, v. 5, n. 9, jan-junho 2016 
matéria tributária ${ }^{9}$. Cabe ao Senado por sua vez, "aconselhar e consentir" junto ao poder Executivo em matérias de política externa ${ }^{10}$.

O Brasil e muitos países, sobretudo os da América Latina, devido ao fato de após a independência não possuírem nobreza ${ }^{11}$, seguiram o modelo presidencialista norte-americano. No caso do Senado, vemos que há pouca variação no modo como é composto, ou seja, por meio de voto majoritário com dois senadores eleitos por estado ou província (Nicolau, 2012). A variação maior se dá na composição da Câmara Baixa, sendo esta formada a partir de voto ou majoritário, proporcional ou misto.

No caso brasileiro, o tipo de votação para a Câmara de Deputados é proporcional, neste caso, se diferenciando do modelo norte-americano, e havendo mais diferença ainda na representação entre Senado e Câmara, pois enquanto o senador congrega interesses diversos, por ser majoritário, um deputado pode representar uma determinada corrente de opinião, grupo de interesse ou a população de uma determinada área geográfica. Segundo Lijphart (1989), o Brasil é um país no qual o uso do sistema bicameral é preferível por possuir um amplo território, muita heterogeneidade entre a população além de diferenças entre tamanho de população e de distribuição de renda entre os estados. O Senado e a Câmara de Deputados, nesta lógica, seriam ferramentas para balançar essas discrepâncias. No que tange às atribuições legislativas, assim como nos Estados Unidos, não há grandes

\footnotetext{
${ }^{9}$ Vide Constituição dos Estados Unidos da América - Artigo 1 (Seção 7).

${ }^{10}$ Ibidem - Artigo 2 (Seção 2).

${ }^{11}$ Com exceção do Brasil, que até 1889 era uma monarquia. A Constituição de 1824 era inspirada no modelo inglês e o Senado tinha sua composição baseada nos moldes da Câmara dos Lordes (Araújo, 2012).
}

Revista Cadernos de Estudos Sociais e Políticos, v. 5, n. 9, jan-junho 2016 
diferenças, o que torna o bicameralismo brasileiro bastante simétrico (Lijphart, 1989; Backes, 1999).

Por fim, vemos que a partir de um país no qual o elemento aristocrático necessário para uma constituição mista não se faz presente, o resultado foi o bicameralismo. A manutenção de duas câmaras serviu para equilibrar demandas de eleitorados diferentes, assim como especificar funções, em grande parte neste caso sem muita diferença entre as casas.

\section{Conclusão}

Não resta a menor dúvida da impossibilidade de conceber um Estado sem poder. O que na verdade se busca verificar é a forma de distribuição e limitação desse poder, da qual se conclui ao longo da história como sendo a mais eficaz e coerente àquela distribuída em funções com suas respectivas esferas de competência e atribuições individuais. Então, passamos a discorrer sobre os principais teóricos da teoria do equilíbrio do poder, partindo de Aristóteles, passando por Políbio, Maquiavel, John Locke, Montesquieu e Federalistas.

Vemos que na Teoria Política, buscar equilibrar o poder sempre foi algo almejado. Inicialmente, podemos sintetizar que a maneira buscada para equilibrar o poder se encontrava no corpo social. Os diferentes elementos sociais (monárquico, aristocrático e democrático) juntos formariam um governo justo e equilibrado, garantindo assim, a liberdade dos cidadãos.

Posteriormente, com a emergência dos Estados nacionais e o governo representativo, combinar elementos sociais se tornou insuficiente. Surge

Revista Cadernos de Estudos Sociais e Políticos, v. 5, n. 9, jan-junho 2016 
então a separação de poderes, para evitar que um representante ou um grupo destes acumulem poder, gerando tirania. Surge daí a noção do "poder controlando o poder". Neste meandro, Montesquieu também ressalta a importância da constituição mista e considera a monarquia constitucional o sistema político mais capaz de assegurar a liberdade. Por fim, os federalistas norte-americanos, dão novos ares à constituição mista, na falta de uma "aristocracia natural" nos Estados Unidos, vindo a resultar no bicameralismo moderno utilizado em uma ampla gama de países.

Revista Cadernos de Estudos Sociais e Políticos, v. 5, n. 9, jan-junho 2016 


\section{REFERÊNCIAS BIBLIOGRÁFICAS}

ARISTÓTELES. A Politica. São Paulo: Lafonte, 2012.

ARAÚJO, Paulo M. "O bicameralismo no Brasil: argumentos sobre a importância do Senado na análise do processo decisório federal". Política e Sociedade, vol. 11, n 21, 2012, pp.83-135.

BACKES, Ana Luiza. Democracia e sobre-representação de regiões: o papel do Senado. Dissertação (Mestrado em Ciência Política). Universidade de Brasília, 1999.

BELLAMY, Richard. "The political form of the constitution: the separation of powers, rights and representative democracy".Political Studies, vol. 44, ${ }^{\circ}$ 3, 1996, pp. 436-456.

BOBBIO, Norberto. A teoria das formas de governo. Brasília: Editora UnB, 1976. . Estado, governo, sociedade. São Paulo: Paz e Terra, 2011.

CHÂTELET, François; DUHAMEL, Olivier; PISIER-KOUCHNER, Evelyne. História das ideias políticas. Rio de Janeiro: Jorge Zahar Editor, 1985.

CHEVALLIER, Jean-Jacques. As grandes obras politicas de Maquiavel a nossos dias. Rio de Janeiro: Agir Editora, 1980.

DAHL, Robert A. A democracia e seus críticos. São Paulo: Martins Fontes, 2012.

HAMILTON, Alexander; MADISON, James; JAY, John. The federalist: acommentary on the Constitution of the United States. Nova York: The Modern Library, 2001.

JANET, Paul. Histoire de la Science Politique dans ses rapports avec la morale. Ulan Press, 2012.

Revista Cadernos de Estudos Sociais e Políticos, v. 5, n. 9, jan-junho 2016 
LIJPHART, A. As democracias contemporâneas. Gradiva: Lisboa, 1989.

LOCKE, John. "Segundo tratado sobre o governo". In:Os pensadores. São Paulo: Abril, 1979.

MANIN, Bernard. "Frontières, freins et contrepoids: la séparation des pouvoirs dans le débat constitutionnel américain de 1787". Revue Française de Science Politique, vol. 44, nº 2, 1994, pp. 257-293.

MAQUIAVEL, Nicolau. Comentários sobre a primeira década de Tito Livio. Brasília: Editora UnB, 1979.

MONTESQUIEU, Charles. “Do Espírito das Leis”. In:Os Pensadores. São Paulo: Abril, 1979.

NEGRI, Antonio. O poder constituinte. Ensaio sobre as alternativas da modernidade. Rio de Janeiro: DP\&A, 2002.

NICOLAU, Jairo. Sistemas eleitorais. Rio de Janeiro: Editora FGV, 2012.

POCOCK, John G. A. "Virtue and commerce on the eighteenth century”.Journal of Interdisciplinary History, vol. 3, n 1, 1972, pp. 119-134.

POLÍBIO. História. Brasília: Editora UnB, 1985.

RABAT, Márcio Nuno. Bicameralismo nos Estados Unidos, na Alemanha e na Inglaterra. Brasília: Consultoria Legislativa, 2002. Disponível em: http://www2.camara.leg.br/documentos-epesquisa/publicacoes/estnottec/arquivos-pdf/pdf/207707.pdf

RIBEIRO DE OLIVEIRA, Isabel de Assis. Teoria política moderna: uma introdução. Rio de Janeiro: Editora UFRJ, 2006.

ROUSSEAU, Jean-Jacques. "Do contrato social”.In:Os Pensadores. São Paulo: Abril, 1979.

TOCQUEVILlE, Alexis de. A democracia na América: leis e costumes. São Paulo: Martins Fontes, 2005.

WEFFORT, Francisco C. (org.). Os clássicos da política vol.1. São Paulo: Ática, 2012.

Revista Cadernos de Estudos Sociais e Políticos, v. 5, n. 9, jan-junho 2016 
WILSON, Francis G. "The mixed constitution and the separation of powers".The Southwestern Social Science Quartely, vol. 15, nº1, 1934, pp. $14-28$.

WOOD, Gordon. "A democracia e a constituicão".In: GOLDWIN, Robert A.; SCHAMBRA, William A. (orgs.).A constituição norte-americana. Capitalismo/Democracia. Rio de Janeiro: Forense Universitária, 1986.

Recebido em: 16/12/2014 Aprovado em: 08/12/2015

Revista Cadernos de Estudos Sociais e Políticos, v. 5, n. 9, jan-junho 2016 